\title{
Interoperability of SME Databases from the Project Management Point of View
}

\author{
Eugen Ştefan Dorel COJOACĂ \\ Bucharest University of Economic Studies \\ eugen.cojoaca@gmail.com
}

The term "Information Society" describes an economy and a society in which access, acquisition, storage, processing, transmission, dissemination and use of knowledge and information play a decisive role. The Information Society implies changes in all areas: administration (egovernment), business (e-commerce), education (distance learning), culture (multimedia centres and virtual libraries) and working (the remote work). At the heart of these transformations is the use of the Internet. The Internet influences how we live, how business is done, how the work is done, how to study, how people interact and how to spend their free time [1], [2]. In this context, this paper purpose is to present the implementation of a project developed by the Ministry of Communication and Social Information from European funds in the sphere of project management, which is different than the management of other IT projects.

Keywords: Project Management, Interoperability, eServices, eGovernment, eBusiness.

1

\section{Introduction}

Project management is the process of coordinating, organizing and managing interdependent activities and allocated resources to ensure that the objectives set to the required quality standards are attained, under conditions of constraints about time, resources and costs. Project management must be carried out by a team of specialists who need to have technical knowledge, knowledge of legislation, knowledge of public procurement and economic knowledge. The project manager will need to carefully plan the assignments of each team member to complete all of the steps described below during the implementation time.

In the case of public institutions implementing projects financed by European funds, project management is much more complex than the management of a project carried out by a private entity for instance. Depending on the value of the project, different stages of project management are required. For projects whose value exceeds $€ 50,000,000$ (major project), project management is done with JASPERS [3], an entity approved by the European Commission, which will cover the project documentation for its approval by the European Union. An example is the RO-NET project, developed by the Ministry of Communications and Information Society with a value of

\subsubsection{EURO.}

Given the particular complexity of this type of projects, we will focus our attention on projects whose value is less than 50.000.000 EURO and which are implemented by most governmental entities in Romania.

The steps for the project manager together with his team have to go through for the implementation of such a project are as follows:

1. The stage of consultation of the guides published by the specialized body (in the case of the programs for the POC (Competitiveness Operational Program) axis it is O.I.P.S.I. (Intermediate Body for Promoting Information Society) the intermediary body for promoting the information society within the Ministry of Communications and Information Society) [4], [5];

2. Complete a financing file that will be reviewed by O.I.P.S.I. to assess the following issues: eligibility, technical and financial verification and selection. Following these evaluations, the application for funding is sent to the Managing Authority (within the Ministry of European Funds) where a final evaluation and approval is made. The final result will be sent to O.I.P.S.I. to conclude the financing contract between O.I.P.S.I. and the applicant;

3. Elaborating the technical documents underlying the drafting of the specifications. 
These fundamental documents are: The Feasibility Study (the form being regulated by the legislation) and the Technical Project in which the technical way of implementing the approved project will be presented. From this stage, the project is also monitored by O.I.P.S.I. through a project officer;

4. These documents will be subject to the approval of the following structures: The Technical-Economic Committee of the public entity (formed by the public-sector specialists) and the Inter-Ministerial Technical and Economic Committee (if the value of the project exceeds RON 2.500.000 without VAT) of ministerial representatives of all existing ministries. Prior to the approval in the Inter-Ministerial Technical and Economic Committee, the project will have to obtain a visa of the Technical Committee of Specialists, which consists of highly technically trained personnel to identify possible issues related to cyber security, interoperability [6], double funding and technological independence.

5. Elaborating the Specifications - this phase involves either the declaration of the Technical Project as the Specification or the much more detailed refining of the technical implementation modalities of the project described in the Technical Project;

6. Following completion of the Specification, it will have to be re-approved by the structures de-scribed in Stage 4;

7. It is worth mentioning that this step is necessary for projects whose value exceeds 30.000.000 RON. It is necessary the opinion of the Technical-Economic Council of the Ministry of Region-al Development and Public Administration of Romania. Discussion of the project within this council requires the elaboration of new documentation in accordance with $\mathrm{OM}$ $1613 / 2013$, un-like the rest of the approvals, which involve only the Feasibility Study, the Technical Proposition and the Task Book;

8. If the project requires Phase 7, a Government Decision containing the technical and economic indicators and the value of the project that the Romanian State will subsequently pay and the re-imbursement by the European Commission will be elaborated and approved;

9. Establishing the contracting strategy will include: the type of public procurement procedure, the supporting documents developed by the procurement department for the publication of the SEAP (Electronic Procurement System) [7] specifications. At the same time, the public entity will submit the proof that it has no debts to the local and central budget of the Romanian state;

10. Before starting the public procurement procedure, all documentation is reviewed and approved by the ANAP (National Authority for Public Procurement), the verification being made in terms of the public procurement evaluation factors. The project manager and the procurement specialist will have to answer all questions from this government entity.

11. The running of the procurement procedure involves:

- Answers to the clarification questions asked by the economic operators interested in winning the auction;

- Developing points of view or legal encounters in case of disputes at this stage;

- Evaluation of the technical and financial offers submitted by the economic operators - within this sub-panel the evaluation committee may ask questions for clarification to the economic agents;

- Elaboration of the procedure report and its approval by ANAP observers as well as by the head of the beneficiary institution;

- Elaboration of legal encounters in case of submitting contestations by economic operators;

12. Signing the contract with the winning economic operator and starting the project according to the execution schedule (the GANTT graph of the project), a graphic that is included in the specifications and in the technical offer of the economic operator;

13. Supervising the actions necessary for the development and implementation of the 
project. In parallel, the project management team prepares the interim reports and repayment requests required by O.I.P.S.I for the project settlement;

14. Implementation of the project ends with a public event and then signing the final acceptance by the project management team.

\section{Content details}

The Ministry of Communications and Information Society has successfully implemented the project „Development of database interoperability SMEs", a project to which we will refer in the following.

In Figure 1 is presented the system architecture implemented by the project „Development of database interoperability SMEs" - a complete interconnection of all the hardware and software components. The software implementation consists of some software modules which are described below.

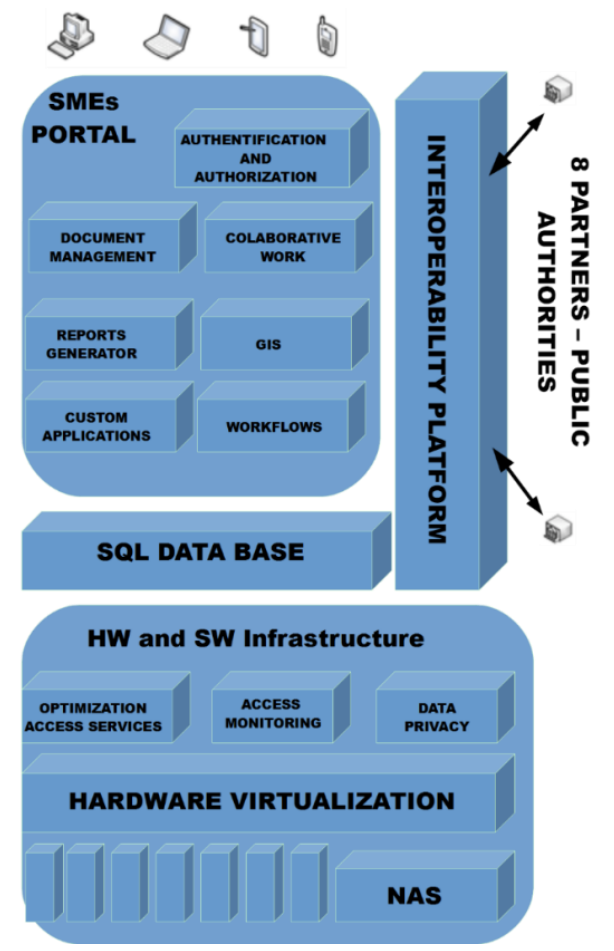

Fig 1. Project implementation scheme for SMEs and Actors

\section{Document management module}

This module enables collaborative work between SMEs, between SMEs and public authorities and between public authorities. In this way, you can put together the documents required for certain activities. For example, when two or more SMEs want to participate jointly in an auction, using this module, all the involved SMEs may have access to documents produced in this regard. Another very relevant example is the case of inter-ministerial committees that can use this module for sharing documents on the working committee. Security plays an important role in the document management module by automating the signing and approval process to any kind of document it uses inside or outside the institution. The signature system allows signing on multiple levels (counter-signatures) and multiple signatures per level (co-signatures) for perfectly mimicking a plain document. [8]

\section{Collaborative working module}

The role of this module is to provide a way in which two or more entities work on the same document. This module provides a chat application that allows communication via the Internet between two or more users.

\section{Module for reports and synthesis}

This module is used by public institutions for aggregating data from several ministries and getting reports to develop public policies and to support business in Romania.

GIS module - This module allows to display the map of SMEs in Romania from their registered address.

Flows Module - This module is dedicated to the automation of activities between public institutions or between SMEs.

\section{Developed applications module}

This module contains a total of 30 applications developed in partnership with eight ministries/public institutions that were partner in this project. The developed applications were divided into three main categories: Business to Business (B2B), Business to Government (B2G) and Government to Government $(\mathrm{G} 2 \mathrm{G})$. All applications follow the rules of automated data synchronization in distributed environments [9].

\section{Applications B2B:}

- Collaborative management useful addresses - mailing list managed collaborative by institutions/legal entities; it is useful in pre-completing certain information (districts / streets/zip codes) based on the integration of service with the Romanian 
Post;

- Labor transfer between SMEs - this application allows recording and posting of surplus/ labor required in Part I of SMEs;

- Get online biannual balance sheet indicators - this functionality provides users with access to financing provided by AIPPIMM;

- Request Service ONRC - Email via direct communication channel with the services offered by ONRC and any requests that may come from SMEs;

- Stock products with reduced economic value - the application is designed for SMEs who consider request - supply transactions on the market of reduced value products.

- Unique street/postal codes nomenclature - the application provides support for retrieving/import postal codes of the localities and pre-fill these date in SMEs profiles;

- Financial products catalog for SMEs banking and financial institutions can record programs and financial offers that are available for SMEs at different time and interest points of their work;

- Cash register - making daily records of cash receipts and payments;

- Romanian Post News Catalog - the Interoperability Portal for SMEs assists SMEs by accessing this application for subscription to various publications of interest.

Applications B2G:

- Check company name - Service for availability check of company's name and redirecting to ONRC website to complete the transaction (booking name, etc.);

- ONRC Service Requests - Email via direct communication channel with the services offered by ONRC and any requests that may come from SMEs;

- Check for insolvent / bankrupt / active Verification service for companies that are under an opened insolvency / bankruptcy requested / declared inactive procedure;

- Electronic endorsement for messaging operators - Electronic information service for the arrival of a mail item on the mail service depending on the provider from which it subscribes;

- Service Tax calculator - Service Type wizard allows users from certain selections of interest (Trade Register, Support) correlated with the type of request, the type of information and its objects, generating a "calculation notes" estimates detailing the fees and / or services desired by the user;

- Subscribe to SEAP services based on CPV codes - using this option, the users can have access to a section with the existing ad auctions from SEAP, filtered by CPV codes;

- Filtering existing procedures in PCU Filter application procedures available for SME user to the relevant profile (as a legal entity) and activity (according to CAEN codes);

- Reimbursement online requests for OIPSI - This application allows users to manage their electronic SMEs refund applications developed by means of projects funded by European and reporting to OIPSI.

Applications $G 2 G$ :

- Validation status for disabled people The application provides the secure and controlled support for public health institutions by institutional protocols to validate certain information such as the status of persons with disabilities;

- Protected unit nomenclature - The SMEs portal provides the Protected Units list by categories through interoperability with the Ministry of Labor. The application provides informational features regarding the laws governing compulsory SMEs with more than 50 employees to use the protected unit;

- Management auditor sites for people with disabilities - By means of this application information, SMEs have the information on the certification activity of SMEs as website auditor with respect to the adaptation of persons with disabilities;

- Authorized SMEs Management- The application offers the access to information 
integration regarding the authorized SMEs to collect the documents necessary in relation to the state;

- Romanian Post Releases Catalog - Interoperability Portal for SMEs assists SMEs in accessing the applications for subscription to various publications of interest;

- Management of supplies and demands The application is for managing information on auctions which are not conducted by SEAP;

- Unique street / postal codes nomenclature - The application offers support for retrieving / import postal codes of the localities and pre-filling these data to SMEs profiles;

- Documents' templates catalog- SMEs have the possibility that certain documents to be completed based on templates provided by public institutions;

- Synoptic table for funding sources and programs - The SMEs Portal provides a summary of information on programs managed by AIPPIMM and facilities offered by these programs;

- Synthetic indicators report - The provided report is dedicated to public and private institutions on a number of financial indicators (side);

- ONRC synthetic indicators report- The report is offered to inform on the financial situation of SMEs, a situation that is registered by ONRC;

- Summary of public available data - Centralization of public information which of interesting for SMEs activity; information is provided by the project partners.

The project management methodology that will be used to successfully complete the activities proposed in this project has the following components:

1. Start-up activities, consisting of:

- Organization of the project bureau and mobilization of the project management team;

- Informing stakeholders about the start of the project, the objectives and the expected re-sults and the request to support the project.

2. General project management activities

- Planning and organizing;

- Coordination and monitoring;

- Control and reporting;

- Activities specific to European projects:

$\circ$ financial management

- ensuring visibility of the project in accordance with the visual identity rules set out in the Visual Identity Manual published on the O.I.P.S.I website;

○ the assurance of the project quality aims to develop efficient systems for verification and maintenance of the technical and financial documentation of the project, which provides security and easy access to these documentation, in the case of monitoring visits or partial and final audits.

The project management team will ensure timely and quality project implementation as well as financial reporting and results in accordance with the contractual provisions.

The team proposed for the implementation of this project consists of employees of the Ministry of Communications and Information Society.

Generally speaking the management team has the following tasks:

In order to implement this difficult project from the management point of view was necessary to have precise tasks for every member of management team.

- project planning, monitoring, and tracking;

- drafting of specifications;

- detailed methodology and supervision of implementation activities at different stages of the project;

- efficient use of financial resources;

- solving economic reports and tracking project funds and drafting financial reports;

- coordination of activities and sub-activities in accordance with the project plan; 
- ensuring the logistical resources necessary for the implementation of all components;

- continuous implementation of the principles of quality management;

- periodic reports;

- human capital management of the project;

- applying public procurement procedures, etc.

The componence of the proposed team and their responsibilities in the project:

\section{Project Coordinator}

Project Coordinator from the Ministry of Communications and Information Society will ensure the fulfilment of the contractual terms of the institution throughout the project. The designated person must have a full understanding of the institution's objectives in order to resolve the is-sues and conflicts of interest arising in the course of the project. Its responsibilities for project coordination are:

- manages the project team to achieve its objectives;

- coordinates, plans and is responsible for the efficient organization of activities approved by the project;

- ensures and is responsible for the correctness, legality, necessity and timelines of operations related to project implementation;

- ensure the smooth running of the project activities and the drawing up of the required documents during the process of project implementation and implementation;

- ensure the confidentiality of the activities and documents produced by the project team members;

- solving the problems that may arise as unforeseen circumstances, including by requesting amendments to the contractual conditions;

- continuously monitoring the project's activities, evaluate the results of the project implementation according to the approved activity chart;
- manages / assists the internal audit activities / programs carried out by company auditors or external auditors;

- correlating actions within the project to maintain information coherence, avoid overlapping skills and limitating the effort of the project team;

- establishes a communication manner with the members of the project team;

- compares the progress of the project with the planned one;

- supervises the Supplier's fulfilment of the obligations assumed under the signed contract;

- signing the documents in accordance with the project plan;

- signing the acceptances.

Financial Accounting Officer must have at least the following responsibilities in the project:

- is subordinated to the project coordinator;

- it will draw up the accounting records and keep the accounting records in order to reflect the project's activities;

- it will prepare the financial reports of the project, partial and final;

- it will keep records of the documents;

- it will participate in the procurement procedures for the award of contracts.

The technical team within the Ministry of Communications and Information Society

The project team will be supported by a technical team whose contribution is needed to achieve the project's objectives and maintain its effects, including the following positions:

- Software Application Administrator;

- Database Administrator;

- Network Administrator (portal).

\section{Project management methodology}

Concretely, specific activities financed by European funds will be carried out as follows:

\section{Purchases}

Responsible: Ministry of Communications and Information Society, supported by Technical Coordinator (TC), and Financial Accounting Officer (RFC).

The internal procurement department of the Ministry of Communications and Information 
Society will ensure the management of the entire procurement process, consisting of: elaborating the award documentation, launching and conducting the procurement procedure and contracting suppliers (for project management and information management consulting services; publishing, IT solutions implementation services).

The procurement team has a good understanding of the current legislation, as it is primarily responsible for the procurement of goods and services necessary for the day-to-day operation of the institution. The project coordinator and his team will be responsible for carrying out the entire procurement process, both for the consultancy contract and for the procurement contract of the IT solution provider.

Within the Public Procurement Compartment, the following tasks are fulfilled:

- Follow-up of public procurement contracts, investment contracts, supply contracts, service con-tracts, works contracts;

- Providing specialized assistance for public procurement of products and services in the field of information society and communications;

- Initiation of public procurement procedures, publication of participation notices and invitations to participate in SEAP. Ensure the proper conduct of government procurement procedures for the award of public procurement contracts for IT \& C projects, acquisition of information and communications equipment, award of public service and product procurement contracts, verification of financial standing and their solvency, the conclusion of the contracts with the winners of the auctions;

- Carrying out procurement procedures for the Intermediate Body for Promoting the Information Society;

- Direct participation, coordination and verification of the awarding documents drawing for the procedures developed by the Ministry of Industry and Trade for awarding public procurement contracts from the Technical Assistance budget;

- Initiating and carrying out public procurement procedures from the Technical Assistance budget;

- Drawing up proposals on the annual procurement program of the ministry financed by the state budget and drawing up the centralizing situation, by objectives, for inclusion in the Ministry's revenue and expenditure budget;

- Preparation of proposals for structural modification of the investment lists of the Ministry; com-piling reports and statistical reports and tracking the process of the investment process; ensuring the conditions for negotiating, checking, monitoring the performance and, as appropriate, updating contracts and conventions, or terminating those that have become unnecessarily low for the ministry regarding investment;

- Performing any attributions regarding the investment activity established by the Director of the Economic, Human and Administrative Division.

Table 1 present details the process of conducting public procurement procedures, the procurement team will use the following model:

Table 1. Process of conducting public procurement procedures

\begin{tabular}{|c|c|c|c|c|c|}
\hline \multirow{4}{*}{$\begin{array}{c}\text { Contract } \\
\text { Value } \\
\text { (without } \\
\text { VAT) }\end{array}$} & \multirow{2}{*}{$\begin{array}{l}\text { Type of } \\
\text { contract }\end{array}$} & \multicolumn{3}{|c|}{ Procurement procedures } & Legislative \\
\hline & & $\begin{array}{l}\text { Direct } \\
\text { purchase }\end{array}$ & Inquiry & Open auction & \multirow{3}{*}{$\begin{array}{l}\text { Law 98/2016 } \\
\text { Law 99/2016 }\end{array}$} \\
\hline & & $<\quad 30.000$ & $<130.000$ & $\geq 130.000$ & \\
\hline & $\begin{array}{l}\text { Services (S) } \\
\text { Goods (B) }\end{array}$ & $\begin{array}{l}\text { Euro or } \\
\text { equivalent } \\
\text { in lei }\end{array}$ & $\begin{array}{l}\text { Euro or } \\
\text { equivalent } \\
\text { in lei }\end{array}$ & $\begin{array}{l}\text { Euro or } \\
\text { equivalent in } \\
\text { lei }\end{array}$ & \\
\hline
\end{tabular}


The procedures mentioned above will be car-

INPUT

Information on existing IT systems

Technical assistance requirements

Analysis of the needs and feasibility study

Terms of reference and assignment documentation for services and goods

\section{Financial Management}

Responsible: Ministry of Communications and Information Society, Financial Accounting Officer (RFC) and Project Coordinator $(C P)$ assisted by the Consultant through Project Manager (MP) and Financial Manager (EF).

For the good management of the budget allocated to the project, until the reimbursement of the requested sums, the consultant's team will develop an expenditure register for the chronological registration of all expenditures ried out in strict compliance with the legislation in force.

\section{OUTPUT}

Service and Goods Contracts

made, broken down into eligible and ineligible, as well as details of the supporting documents and actual payment data.

The expenditure verification step is intended to ensure that all expenditure conducted under the project is compliant with the Applicant's Guide, the financing contract and the legislation. At the same time, the reimbursement requests which will accompany the progress reports will be submitted for approval to O.I.P.S.I.
INPUT

Accounting documents (invoices, payment orders, etc.)

Expense plan

Project budget

Support will also be provided by the Financial Accounting Compartment, which has the following tasks:

- Signing of the payment documents, both in cash and by transfer, of the various payment obligations of the Ministry of Communications and Information Society, including the payments of Technical Assistance, ordered by the authorizing officer;

- Coordinating the elaboration of various economic and financial analysis papers requested by different governmental institutions and bodies with which the ministry cooperates;

- Verification and centralization of returns for internal and external travel, steady expenses, protocol etc.

- The evidence of tangible and intangible fixed assets and the calculation of depreciation of fixed corporate assets;

\section{OUTPUT}

\section{Expenditure register}

Claims for reimbursement

- Keeping records of budget, legal commitments, proposals for the commitment of expenses and payment entitlements;

- Preparation of accounting notes and synthetic and analytical sheets of the accounts in lei and currency with which the institution works;

- Preparation of analytical and synthetic verification balances;

- Evidence of debtors and suppliers;

- Effective management of existing material and technological resources.

\section{Elaboration of progress reports and re- imbursement requests}

Responsible: Ministry of Communications and Information Society through the Project Coordinator (CF) and Financial Accounting Officer (RFC), assisted by Consultant through Project Manager (MP) and Financial Man$\operatorname{ager}(R F)$ 
The selected Consultant team will provide support to the Ministry of Communications and Information Society in order to achieve the progress reports set out in the financing agreement. Thus, progress reports will be prepared by the Project Manager and forwarded to the Project Coordinator from the Ministry of Communications and Information Society, who will verify and sign the above-mentioned reports. Progress reports will be based on the activity reports transmitted monthly by the Project Manager and discussed in the monitoring meetings.

These reports will comply exactly with the requirements specified in the Applicant's Guide and in the financing agreement signed with OI.P.S.I. and will be filed with OI.P.S.I. at the deadlines set by the contract, together with all other documents expressly required by the grant agreement.

Reimbursement applications that will be attached to the progress reports will be prepared by the Project Manager with the support of the Financial Officer and the reimbursement file will be prepared in accordance with the requirements specified in the contract and will contain all the supporting documents necessary to verify the eligibility of the expenditure incurred and payment.

INPUT

Project budget, cost register, accounting documents - certified copy

The financing contract

Activity reports of Service Providers and Goods

\section{Archiving documents}

Responsible: Ministry of Communications and Information Society, Project Coordinator $(C P)$ assisted by Project Manager (MP), Financial Manager $(R F)$ and Expert Structural Funds (EF)

According to the Community regulations, the audit circuit (audit trail) is the establishment of in-formation flow, the duties and responsibilities related to it, as well as the archiving of complete supporting documentation for all stages of an action, while allowing the reconstruction of operations from the total amount to individual details and vice versa.

The audit trail is therefore a chronological record of the project activities to allow the reconstruction and examination of the sequence of events and / or changes.

The applicant will prepare and ensure an adequate audit trail by keeping and archiving documents so that they are not altered by human and time factors.

Thus, with the support of the Consultant, the Ministry of Communications and Information Society will take the following measures:

\section{OUTPUT}

\section{Progress reports}

Claims for reimbursement

- Original copies of invoices and documents attesting payment will be kept by the Ministry of Communications and Information Society at the location of the project together with a certified copy both in paper and electronic form (CD / DVD, etc.);

- The documents elaborated within the project will be kept as follows: 1 original copy and 1 copy on paper and in electronic version;

- The reports, reimbursement requests and other official documents requested by the OIPSI will be drafted in an original copy and the number of copies established under the financing con-tract, to be handed over to the OIPSI, and a certified copy will be kept, at the project site;

- The archiving will be done at the completion of the project, the complete file with the original documents will be kept in a protected space, together with a CD / DVD containing all the scanned documents, remaining at the location of the project during the legal archiving and retention period post-implementation). 
INPUT

Project budget and expenditure register, accounting documents - in original and certified copies

The financing contract

Progress reports and reimbursement requests, other documents produced within the project The archiving procedure

\section{Ensuring the visibility of the project}

Responsible: Ministry of Communications and Information Society, Project Coordinator $(P C)$, assisted by Consultant through Project Manager (PM) and Expert Structural Funds (EF)

This activity has a particular importance in the dissemination of the funding opportunities made available to the public administration for the development of information systems in order to improve the quality of services to citizens and the business environment. The information and publicity activity will be in compliance with EU regulations and will be prepared by the Public In-formation and Press Relations Service of the Ministry of Communications and Information Society, together with the selected consultant, and will run INPUT Information and publicity plan, project information

\section{Minimum requirements for project man- agement}

The project management consultant to be contracted will meet the following minimum requirements:

It must have specialists in the following areas:

- Project management;

- Grant funds;

- Financial;

- Information and Advertising;

- Training / Training in Project Management;

- Information and communication technology.

\section{OUTPUT}

Files/cassette box, correctly inscribed and retained

Copy the hard copy of the project into electronic support

throughout the project.

The competencies of the Public Information Service and press relations are as follows:

- Coordinating the ministry's work with the media, other institutions in the public system, with private sector organizations or civil society;

- Supervising the organization and conduct of activities initiated by the ministry or in which the ministry is involved, including seminars and round tables or other actions alike, dissemination of information or public awareness; for these purposes, they may contract consultation, expertise, technical assistance, in accordance with the legal regulations in force;

\section{OUTPUT}

Press releases and communicated on the website of the Ministry of Communications and Information Society

Start and finish events of the project

Informative flyers and posters

\section{Project Manager. Tasks and responsibil- ities}

The Project Manager reports directly to the Project Coordinator and will ensure the coordination of the consultant team and assistance to the Project Coordinator designated by the Ministry of Communications and Information Society.

Responsibilities:

- Single point of contact in relation to the Beneficiary;

- Monitoring the implementation of the project;

- Elaboration of the revised activity plan and follow-up of the project deadlines; 
- Elaboration of Progress Reports to be submitted for approval to the Ministry of Communications and Information Society;

- Performing, in collaboration with the financial officer, the reimbursement requests;

- Monitoring financial management, including expenditure verification;

- Identify the risks and ways of mitigating I avoiding them;

- Supervises the supplier's fulfilment of the obligations assumed under the signed contract;

- Elaboration of the document archiving system and provision of the audit trail to the beneficiary;

- Coordinating the information and publicity activities related to each stage of the project;

- Ensuring easy access to project documentation to conduct partial and final financial and technical audits.

II. Expert Structural Funds. Responsibilities:

- Drawing up quarterly progress reports;

- Drawing up the progress reports accompanying the reimbursement request;

- Drawing up the Reimbursement Requests;

- Archiving the final folder with the documents generated within the project (5 years post-implementation).

III. Financially responsible. Responsibilities:

- Elaborate, together with the Project Coordinator from the Ministry of Communications and In-formation Society, the expenditure plan;

- Checking the availability of the financial resources needed to initiate the project;

- Assistance in preparing the pre-financing application;

- Expenditure verification;

- Verifying the financial aspects of public procurement contracts;

- Elaboration of the reimbursement file;

- Contributing to the development of progress reports;
- Ensuring access to the financial-accounting documentation for the external auditor;

- Transfer of specific financial management knowledge to the implementation team.

IV. Technical project manager. Responsibilities:

- Managing the system implementation (hardware components; software; security);

- Coordinating the entire technical team, assigning tasks to each member of the team;

- Providing a functional email address to facilitate communication between the project team and the beneficiary;

- Providing resources for executing implementation services included in the specification;

- Maintain and apply risk management and quality assurance procedures;

- Draw up all necessary reports according to the project requirements and / or other reports is-sued by the Project Manager.

IV. Technical project manager. Responsibilities:

- Managing the system implementation (hardware components; software; security);

- Coordinating the entire technical team, assigning tasks to each member of the team;

- Provides a functional email address to facilitate communication between the project team and the beneficiary;

- Provides resources for executing implementation services included in the specification;

- Maintain and apply risk management and quality assurance procedures;

- Draw up all necessary reports according to project requirements and / or other reports issued by Project Manager.

VI. Hardware Infrastructure Architect and Communications. Responsibilities:

- assessing the needs of the hardware and communications infrastructure, as well as implementing the communication part of 
the project;

- Reporting the state of implementation of the solution to the Project Manager and to the Project Coordinator from the Ministry of Communications and Information Society.

VII. Expert business analyst. Responsibilities:

- Conducts consultancy studies on organizational aspects in the development of ICT systems;

- Analyses and defines work-flow processes and elaborates the specifications of the pro- cesses;

- Coordinates analysis of data exchange requirements with all involved structures and develops the diagnostic report.

VIII. Specialist in information and publicity. Responsibilities:

- it ensures the information and publicity of the project according to the U.E.

- it makes the press releases / announcements;

- it organizes information events within the project;

- it makes promotional materials.

IX. Technical documentation specialist and quality assurance. Responsibilities:

- Prepares all the supporting documentation related to the implementation and transfer of know-how to the Beneficiary;

- Follows the implementation of software development / installation / testing / validation of the methodologies;

- Pursues quality assurance in software development / installation / testing / validation;

$X$. Specialist in vocational training / education. Responsibilities:

- Provides training in project management; The monitoring procedure used by the management team

The monitoring process involves obtaining information that allows knowledge and understanding of the project stage at a given mo- ment, as well as the trends in the activities included in the project. Monitoring can be done through discussions with the personnel involved in the project, by recording the results and the problems that have arisen, by observing the activities carried out. The ongoing monitoring of the project (monitoring activities, stage of the plans, costs, results of the project) allows reporting of its realization, thus obtaining the information whose processing supports the reporting process.

The process of monitoring the contracted project management team will include, but is not limited to, the following:

- Delivering timely documents and reports, respecting the requirements of the Applicant's Guide, the Financing Agreement and its annexes, the European procedures, the relevant Romanian legislation, the plan of activities and the deadlines set and submitted for approval to the Beneficiary;

- Information / publicity activities (for audit and information and publicity services where applicable) are implemented according to the information / publicity plan and in accordance with the Visual Identity Manual;

- The procurement activities are finalized according to the project planning, being implemented according to the Romanian legislation;

- Progress reports based on project activity reports provided by the Consultant are approved by OI PSI;

- Reimbursement claims submitted to the OIPPI. and developed with the assistance of the Project Manager;

- The quality and transparency of the archiving and recording system will be monitored through the ease of access of the specialists who will perform the partial and final technical and financial audits of documents, equipment and solutions and technologies.

Table 2 present the timetable for monitoring activities: 
Table 2. The timetable for monitoring activities

\begin{tabular}{|c|c|c|c|c|c|c|c|c|c|c|c|c|}
\hline \multirow[t]{2}{*}{ Monitoring activities } & \multicolumn{12}{|c|}{$\begin{array}{l}\text { Monitoring period (each cell represents } 1 \text { cal- } \\
\text { endar month) }\end{array}$} \\
\hline & 1 & 2 & 3 & & & 6 & 7 & 8 & 9 & 10 & 11 & 12 \\
\hline \multicolumn{13}{|l|}{ Monitoring sessions } \\
\hline \multicolumn{13}{|l|}{ Cost control } \\
\hline \multicolumn{13}{|l|}{ Monthly activity reports } \\
\hline Progress reports & & & & & & & & & & & & \\
\hline
\end{tabular}

The consultant's team, the internal team of the institution and the Project Coordinator will meet twice a month in a two-hour session so that the information discussed can be transmitted, assimilated and implemented within a short period of time. Bilateral monitoring sessions will be finalized with some minutes that will be signed by all participants and will be archived in the original. Copies of the minutes will be sent to each participant and the measures implemented will be dis-cussed at the opening of the next meeting.

Project monitoring will follow the criteria specified above and will be consistent for both team members to implement the project, both Consultant representatives and employees of the institution.

This activity will be based exclusively on quantifiable data, indicators and sources of pre-approved verification at the start of the project, when the Project Plan and project milestones were based on the minutes of the meetings the previous monitoring and on the terms and conditions set out in other documents elaborated within the project (procurement plan, information and publicity plan etc.).

\section{Conclusions}

Project implemented by the Ministry for Information Society is open and scalable so that its further development will be very easy to do. The new electronic services will become available to all users, because there will be an adequate infrastructure, the deployment will be centralized and the integration will follow the European standards. Each user will have a unique identity to all services due to secure authentication. Costs for SMEs and Central Administration will be reduced because the project offers:
- Common infrastructure;

- Reduced processing times;

- Eliminate redundancy;

- Guaranteed quality and safety services.

The economic agencies will provide access to two types of information:

- public - general information and public documents, schedules, operating committee's powers of government structures;

- private - dedicated application providing the possibility of creating a direct and secure connection with public administration, where personal access data that are used or required are protected.

The project "Development of database interoperability SMEs" was successfully implemented by the Ministry of Communications and Information Society and all the amounts invested by the Romanian state were fully reimbursed by the European Commission following all the stages described by this paper. Project teams need to have knowledge in areas such as public procurement, finance, European and technical funds, due to the fact that the Romanian Public Procurement Law contains over 1000 articles and the European funds legislation besides the laws governing public finances must be taken into consideration. This is a main reason which leads to difficulties in the implementation of projects financed by European funds.

At the present moment, there are no complex courses presenting all the stages of implementation for a project funded by European funds, starting with the preparation of the documentation for the submission of a project and finishing with the reimbursement and the sustainability of the project. The published guidelines were incomplete or they were treating certain sections of this ample process, for 
which reason financial corrections occurred and implicitly the costs for the Romanian state has increased.

\section{References}

[1] Digital Single Market - Projects about eGovernment https://ec.europa.eu/digitalsingle-market/en/projects/75991 - Accessed October 2017

[2] Government Transparency Institute - Corruption in EU Funds Europe-wide evidence on the corruption effect of EU funded public contracting http://www.govtransparency.eu/wp-content/uploads/2015/11/GTI_WP2015_1_Fazekas_Toth_150619.pdf - Accessed October 2017

[3] http://ec.europa.eu/regional_policy/ro/ funding/special-support-instruments/jaspers/ - Accessed October 2017

[4] http://fonduri.mcsi.ro/?q=node/5 - Accessed October 2017
[5] http://www.fonduri-ue.ro/poc-2014 - Accessed October 2017

[6] https://www.comunicatii.gov.ro/mcsi-cadrul-national-de-interoperabilitate - Accessed October 2017

[7] https://www.e-licitatie.ro/Public/ Common/Content.aspx?f=PublicHomePage Accessed October 2017

[8] Florin Pop, Ciprian Dobre, Decebal Popescu, Vlad Ciobanu, Valentin Cristea, Digital Certificate Management for Document Workflows in E-Government Services, Infrastructure - 9th IFIP WG 8.5 International Conference, EGOV 2010 Lausanne, Switzerland, ISBN 978-3-64214798-2, Springer Ed., September 2010

[9] Vlad Ciobanu, Florin Pop, Decebal Popescu, Valentin Cristea, A Distributed Approach to Business Intelligence Systems Synchronization - 12th International Symposium on Symbolic and Numeric Algorithms for Scientific Computing, Timișoara, 2010,

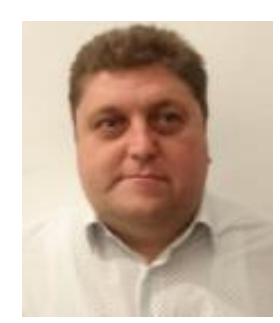

Eugen Cojoacă, graduated of the National School of Political and Administrative Studies, Faculty of Public Administration - Public Management, Master's Program "Public Affairs Management", currently PhD student at the Institute of Doctoral Studies at Bucharest university of Economic Studies, Computer Science. Since 2008, I have worked in the Central Public Administration as the Secretary General of the National Authority for Regulation and Monitoring of Public Procurement, then Deputy Secretary General of the Ministry of Communications and Information Society, where I have implemented numerous projects IT funded by European funds. I was the coordinator of an operational procurement manual and published two ISI indexed articles. 